\title{
DA tRANSGRESSÃO AO CONTROLE: UMA ANÁLISE DOS GRAFITES DO MURO DO Jockey Club do Rio de Janeiro
}

Hely Geraldo Costa Júnior ${ }^{1}$ Universidade Estácio de Sá, Rio de Janeiro, Brasil

\begin{abstract}
Este artigo analisa os grafites do muro do Jockey Club do Brasil no Rio de Janeiro, suas relaçóes com o território, o mercado e o capital. O enorme muro grafitado de forma livre, espontânea e transgressora desde o início dos anos 2000 passou por uma reforma e restauração em março de 2014. A ação apagou todas as imagens que multiplicavam-se pelos seus mais de dois mil metros de extensão, causando polêmica e indignação entre grafiteiros e população. Meses depois, um novo painel foi criado em substituição ao antigo, porém, de forma institucionalizada, com curadoria na escolha dos grafiteiros, patrocinio e apoio estatal. Do muro transgressor ao muro controlado, a análise que se segue fundamenta-se sobretudo nos conceitos de poder e sociedade disciplinar propostos por Michel Foucault, e sociedade de controle, desterritorialização e reterritorialização de Gilles Deleuze e Félix Guattari.
\end{abstract}

Palavras-chave: grafite, transgressão, poder, sociedade disciplinar, sociedade de controle, Rio de Janeiro.

\section{INTRODUÇÃo}

Este artigo é fruto de uma pesquisa sobre a cooptação e a mercantilização do grafite carioca, desenvolvida durante o doutorado em design da Pontifícia Universidade Católica do Rio de Janeiro, entre março de 2012 e janeiro de 2016, utilizando-se da cartografia proposta por Deleuze e Guattari (1995a; 1995b) como recurso metodológico, em um processo plural, aberto e multidimensional. Uma cartografia que buscou analisar os deslocamentos ideológicos da prática; as relações e os jogos de poder envolvidos no mercado de arte urbana; os enfrentamentos, as lutas e as forças presentes nos muros e nas paredes da cidade; os modos de subjetivação e as

1 Contacto do autor: falecom@hely.com.br. 
práticas de resistência e de liberdade presentes nas ruas do Rio de Janeiro. Procurou identificar e analisar os campos de força, as relações e os movimentos do grafite no tempo e no espaço da Zona Sul carioca. Uma pesquisa-rizoma desenvolvida num plano horizontal, de forma acêntrica, indeterminada e não hierarquizada, abrindo-se para a pluralidade, tanto de interpretações quanto de ações.

O método de pesquisa consistiu no acompanhamento dos processos e dos devires que constituem o campo social do grafite no Rio de Janeiro. Os resultados apresentados não devem ser entendidos como metas prefixadas ou amplamente pensadas. Pelo contrário, foi a experiência da pesquisa que redefiniu suas próprias metas durante o percurso (Passos et al., 2009). O método cartográfico foi traçado no e a partir do plano da experiência do cartógrafo-pesquisador, que se envolveu na rede dos agenciamentos entre sujeito e grafite, a fim de compreender o cenário do grafite carioca, suas configurações territoriais, efemeridades e transitoriedades. Por tratar-se de um método que não parte de um modelo preestabelecido, procurou-se indagar a cooptação do grafite carioca a partir de uma fundamentação própria, de forma a buscá-lo diante da complexidade. Como afirmam Guattari e Rolnik (2005), o objetivo não era revelar sentidos, mas criá-los a partir do contínuo movimento de ressignificação.

Para além de toda aceitação e popularidade que o grafite alcança na atualidade, sua prática esteve, por muito tempo, guiada pela transgressão e pela marginalidade. Hoje, a subversão parece ser controlada enquanto muitos grafiteiros adequam-se, pouco a pouco, ao modo de produção capitalista. As esferas econômica e subversiva, aparentemente contraditórias, passaram a combinar-se de forma inseparável. Por influências e poderes diversos, criou-se uma cultura intensa de valorização da prática e do produto do grafite, na qual os modelos econômicos passaram a influenciar, em grande parte, a forma, o local e seu modo de produção e exibição. Enquanto uma parte dos grafiteiros abandonam a clandestinidade, ganham fama, status de artista e tornam-se corpos dóceis, forças produtivas para a sociedade, outra grande parte permanece na clandestinidade urbana, sem qualquer reconhecimento artístico ou social.

No Rio de Janeiro, o grafite teve suas primeiras aparições na década de 1970, com o aparecimento de frases como "Celacanto provova maremoto" e da assinatura "Lerfá Mu", sobretudo nos muros e paredes da Zona Sul da capital (Silva 2012). Inscrições por estudantes universitários, que as reproduziam em grupos pelas madrugadas, causavam curiosidade e espanto na população, que questionava a origem e a intenção das frases, que não passavam de brincadeira. Anos mais tarde, na década de 1990, o grafite ganhou força pelas mãos de grupos da Zona Norte, do subúrbio e da cidade de São Gonçalo. No entanto, somente quando jovens de classe média, muitos deles estudantes universitários de design, levaram-no para os muros e as paredes da Zona Sul, no início dos anos 2000, é que as atenções se voltaram para a prática de maneira positiva.

Em 1998, Tomaz Viana, o Toz, e Bruno Bogossian, o BR, eram estudantes de design, rapazes de classe média da Zona Sul, e decidiram criar um grupo para grafitar. Nascia o FleshBeck Crew (...). Tudo começou no curso de design da Faculdade da Cidade, com a produção de uma pequena revista, a "Zine", com muita inspiração nos quadrinhos. Os rapazes iniciaram as suas incursões pelo Centro da cidade para logo depois investir nos muros da Zona Sul (...). O reconhecimento do que os rapazes faziam nos muros trouxe trabalho. Primeiro, o FleshBeck montou um escritório de design, que assinou projetos para a Coca-Cola, H.Stern, entre outras grandes empresas, e também para ambientes de restaurantes, boates e lojas (Silva, 2012:34). 
Atualmente, o grafite é reconhecido e em muitas situações regimentado pelo poder público através de decreto municipal. A prefeitura da cidade instituiu o Dia Municipal do Grafite (27 de março) e inaugurou, em 2015, a primeira galeria municipal de arte urbana, a GaleRio. Além de criar o EixoRio, um órgão de articulação entre o poder público e os grafiteiros, que tem como principal proposta a revitalização da cidade por meio da chamada arte urbana. A cidade conta com dois grandes eventos anuais que têm o grafite como temática: o ArtRua, festival de arte urbana ligado à feira internacional de arte ArtRio, e o Art Core, que une grafite, skate e cultura urbana nos jardins do Museu de Arte Moderna durante três dias. Além disso, diversas ações institucionais e comerciais vêm utilizando-se do grafite e sua linguagem, como por exemplo, a pintura da fachada do Hotel Marina Palace, um dos mais tradicionais hotéis da orla do Leblon, pelo grafiteiro Toz. E também a pintura do maior mural de grafite do mundo pelo grafiteiro paulista Kobra, em razão das Olimpíadas que aconteceram na cidade em agosto de 2016.

Nesse contexto, este artigo busca realizar uma leitura sobre o muro do Jockey Club, na Zona Sul do Rio de Janeiro. Devido ao projeto de revitalização e manutenção, o muro do conjunto arquitetônico, antes um importante mural, com centenas de grafites criados coletivamente desde o início dos anos 2000, foi pintado na cor bege em março de 2014. Apagados sem aviso prévio, os trabalhos de autoria de grafiteiros cariocas, brasileiros e estrangeiros se perderam na revitalização. $\mathrm{O}$ espaço era considerado um dos mais importantes e disputados para a prática do grafite no Rio de Janeiro, devido à sua extensão e, especialmente, à sua localização privilegiada, em região de classe média alta, num dos principais corredores de tráfego urbano carioca.

Após uma série de protestos em redes sociais e uma considerável cobertura da mídia, um acordo entre a prefeitura e a instituição permitiu que outro muro do clube, não tombado pelo Patrimônio Histórico, fosse novamente pintado por grafiteiros. $\mathrm{O}$ processo, no entanto, aconteceu de forma institucionalizada, a partir de uma curadoria que escolheu os grafiteiros que participariam do novo projeto batizado de "Jockey Club Art Urbana”.

\section{O MURO GRAFITADO}

O primeiro grafite do muro do Jockey surgiu em 2000, pelas mãos do grafiteiro Acme, numa homenagem ao músico Marcelo Yuca, do grupo musical O Rappa, baleado em um assalto. A partir de então, o local foi tomado pelos mais diversos grafiteiros, cariocas, brasileiros e estrangeiros, nos anos que se seguiram (Lima 2014). Muitas de suas representações eram de personagens lúdicos, personagens de telenovelas, como a vilã Odete Roitman, atores de cinema norte-americano, como Willem Dafoe, músicos da banda Joy Division, Jimy Hendrix e sambistas como Cartola e Zé Kéti. Em menor proporção, havia também grafites ligados a temas sociais, com imagens de crianças abandonadas ou frases de protesto nos quase dois mil metros de extensão do muro (Figura 1).

Localizado na Zona Sul do Rio de Janeiro, reconhecida como o ponto onde se concentram as elites econômica e cultural da capital. Presente no imaginário popular, amparado pela mídia, nas novelas de televisão e nas campanhas de marketing, a região é conhecida como o lugar onde habitam os ricos e os famosos, um espaço idealizado rodeado de belas paisagens, os melhores bares, restaurantes, cinemas, teatros etc. 
Nesse ambiente privilegiado, os grafiteiros buscavam reconhecimento e visibilidade. Ao transformarem o muro do Jockey Club em uma singular e concorrida tela coletiva a céu aberto, seus trabalhos ganhavam destaque em meio à elite, formadora de opinião. Trabalhos híbridos, sincréticos e transculturais, como define Canclini (2008), os grafites realizados se pautavam pela diversidade de temáticas, significações, estilos, referências e técnicas e pela própria origem das pinturas que ali surgiam. Figuras, caricaturas, cartuns, formas abstratas e inscrições que combinavam e se misturavam de forma a gerar novas estruturas, novas alianças. Uma hibridação que despontava da criatividade individual e coletiva, ao provocar a transformação de um muro e reinseri-lo em outro contexto, um lugar de "interseção entre o visual e o literário, o culto e o popular" (Canclini 2008: 336). Uma espécie de inscrição territorial do meio urbano que o demarcava de maneira única e, também, evidenciava-o fortemente ligado ao espaço e ao território físico que ocupavam no ambiente urbano, os grafites do Jockey eram também uma prática social e uma forma de expressão que ganhavam visibilidade e consistência a partir da ocupação do muro. Marcas que revelavam o domínio público sobre um espaço privado e sinalizavam conflitos, lutas e embates na organização, delimitação, articulação e apropriação simbólica daquele território por parte dos grafiteiros.
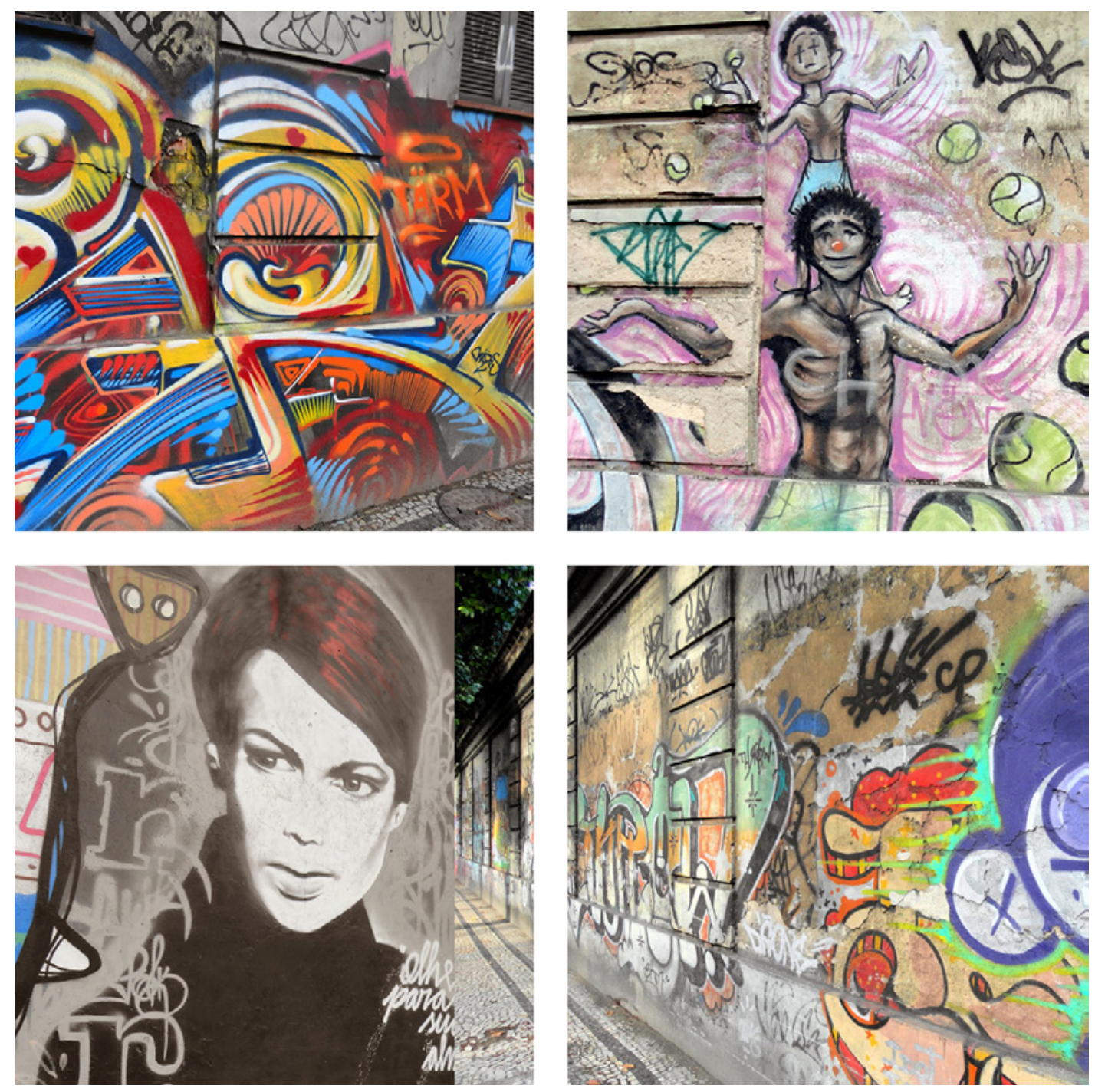

Figura 01 - Detalhes de grafites encontrados no muro do Jockey Club Brasileiro, antes da pintura de revitalização (fotos Hely Costa Jr.). 
Uma prática estranha ao espaço geométrico de uma grande cidade como o Rio de Janeiro, diretamente ligada a formas específicas de operações e que proporcionam novas visibilidades (Certeau 1994). Os grafites pintados sobre o muro do Jockey Club transformavam poeticamente aquele lugar ao transformá-lo em um lugar praticado. Com as acepções e sentidos que podem ser suscitados a partir de leituras e interpretações que despontam junto às questões estéticas, o muro do Jockey poderia ser classificado também como o que Cassirer (Apud Harvey 2002) denomina de um "espaço simbólico". Uma espécie de espaço abstrato, que gera significações e é marcado pelo estabelecimento de formas arquitetônicas e pictóricas. Ou ainda, "espaços de representação" (Lefebvre 2000), nos quais surgem os significados, emoções e onde as sensações são concebidas, experimentadas e incorporados no modo de vida. Um espaço que era parte da maneira de viver, uma representação ao mesmo tempo material e emocional, por meio de imagens, formas, cores e palavras que ali estavam contidas.

Tratava-se de uma obra polifônica, surgida em uma cidade polifônica (Canevacci 2005), criada e modificada pelos mais diversos agentes e diferentes vozes durante um largo período. Uma representação dos encontros, dos conflitos e das vozes dissonantes que habitam, circulam ou usufruem daquele espaço em comum. Com múltiplas entradas e leituras, o muro tornou-se um painel no qual os grafiteiros, das mais diversas origens, entoavam ao mesmo tempo as mais diferentes ideologias. Um espaço de interações sociais, nas quais emergiam o sentimento de pertencimento, as memórias coletivas e o compartilhamento de ideias (Goodsell 2003). Um local elementar, processado por práticas humanas, onde a cidade do Rio de Janeiro era, ao mesmo tempo, espaço físico e também imaginário, no qual se construíam as diferenças, a vida urbana e o espaço: "ao adotar esses espaços da vida cotidiana, os artistas e suas obras apresentam desejos utópicos de reaproximação entre o sujeito e o mundo" (Campbell 2015: 20).

Ao tomarem o muro do Jockey com suas pinturas, desenhos e inscrições, os grafiteiros subvertiam aquele lugar e também o seu significado, ao transformarem sua superfície em uma grande tela. Os grafites "questionam o próprio sentido da cidade, tal como este é entendido por aqueles que nela vivem e pelos agentes da planificação, ignorando o usufruto do espaço socialmente aceito" (Campos 2009: 5). Uma forma de resistência cultural, que mudava os padrões estéticos, operava sobre as linguagens e redefinia aquele espaço urbano e se constituía a partir da própria transformação: ao escrever, rabiscar ou desenhar sobre o antigo muro, onde os grafiteiros tornavam a prática do grafite uma maneira evocativa de tomá-lo para si, por resistência ou contestação (Ferrel 1996).

É o que Lefebvre (2001) define como o "direito à cidade", que diz respeito a uma visão política sobre a produção do espaço social em detrimento a uma visão puramente administrativa e capitalista. Trata-se do direito, não só de desfrutar os espaços urbanos mas, sobretudo, de maneiras democráticas de habitar e vivenciar a cidade. O direito de estabelecer o modo de vida urbana, transformado e renovado, no qual cada indivíduo membro da sociedade tenha espaço e liberdade para manifestar seus ideais e suas diferenças. Mais que a simples melhoria da qualidade de vida da população, trata-se da produção de um espaço vinculado ao valor de uso e não ao valor de troca. Um direito superior, referente à liberdade e aos modos de habitar e socializar. Harvey (2013) completa o pensamento e diz que se trata do direito de transformar a cidade a partir do desejo de seus habitantes. Ao modificá-la, estamos nós mesmos nos modificando. Reconfigura-se a cidade, e ela, em seguida, reconfigura-nos. 
Por esse motivo é importante pensar sobre os conflitos éticos e estéticos, a substituição dos grafites pela pintura bege, que revela os modelos culturais, sociais e econômicos estabelecidos nas cidades, que muitas vezes não possibilitam devidamente a livre circulação de todos os seus habitantes, suas ideologias e pensamentos. Enquanto o muro grafitado servia de suporte, ou mesmo de mídia, para aqueles grafiteiros que o transformaram ao longo do tempo, a pintura bege condiz com os valores de outros grupos sociais que também habitam o espaço.

\section{O MURO CONTROLADO}

A revitalização do muro e a consequente destruição dos grafites ali presentes geraram uma onda de polêmica e indignação, tanto entre grafiteiros, como entre a população, sobretudo nas redes sociais da Internet. De acordo com o grafiteiro Bruno Big,

Apesar de saber que a nossa arte é efêmera, imagino que todos os artistas ficaram muito insatisfeitos com essa situação. No muro de Berlim, fizeram a East Side Gallery. Os artistas que pintaram o muro nos anos 90 foram chamados para repintar suas obras na parede (Lima 2014: s/p).

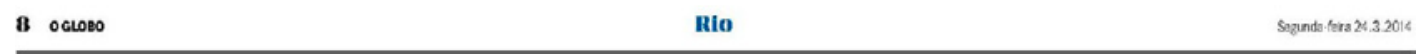

\section{Polêmica estampada nos muros do Jockey}

Com tinta bege, clube apaga obra de arte urbana coletiva e alega que medida é para revitalização
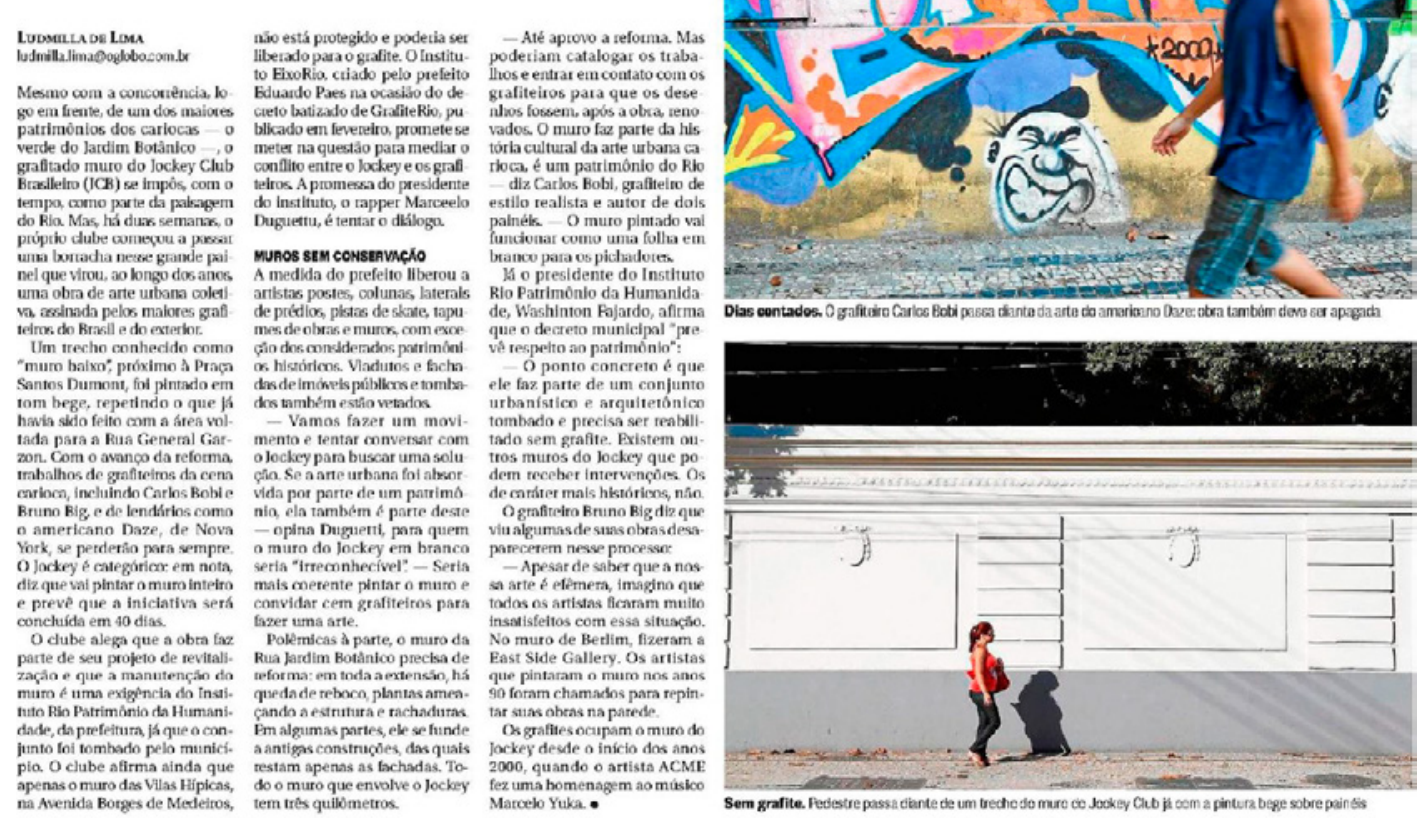

Figura 2 - Jornal O Globo, de 24 de março de 2014.

Matérias e reportagens em jornais, revistas e sites relatavam, em março e abril de 2014, a reforma e a pintura do muro e o apagamento do maior mural de grafite da cidade até então 
(Figura 2). O muro do Jockey era um tipo de representação que influenciava o cotidiano e a existência dos indivíduos, ao se incorporar de maneira sutil à rotina daqueles que circulavam ou vivenciavam o ambiente ao redor. De forma que aqueles grafites tornavam-se elemento integrante de suas experiências diárias.

Em julho do mesmo ano, meses após o apagamento do antigo muro do Jockey, André Bretas, marchand, dono de galeria de arte e diretor do Instituto RUA - Revitalização Urbano Artística, uma associação civil que visa criar e desenvolver projetos de ocupação e revitalização do espaço público por meio do grafite e da arte urbana, criou o projeto "Jockey Club Arte Urbana”.

O projeto consistiu na pintura de um outro muro do próprio Jockey Club, este na Av. Borges de Medeiros (Figura 3), também local de grande movimento e voltado para a Lagoa Rodrigo de Freitas, importante ponto turístico da cidade. O Instituto RUA realizou a curadoria e a escolha dos grafiteiros que poderiam se utilizar do espaço. Entre os nomes convidados estavam alguns dos mais renomados da cidade: os cariocas Marcelo Eco Marchon, Bruno BR, Acme, Criz Silva, Akuma e o coletivo Acidum Project, de Fortaleza. Cada um deles escolheu mais três artistas para a criação do mural, totalizando em cerca de 15 grafiteiros.

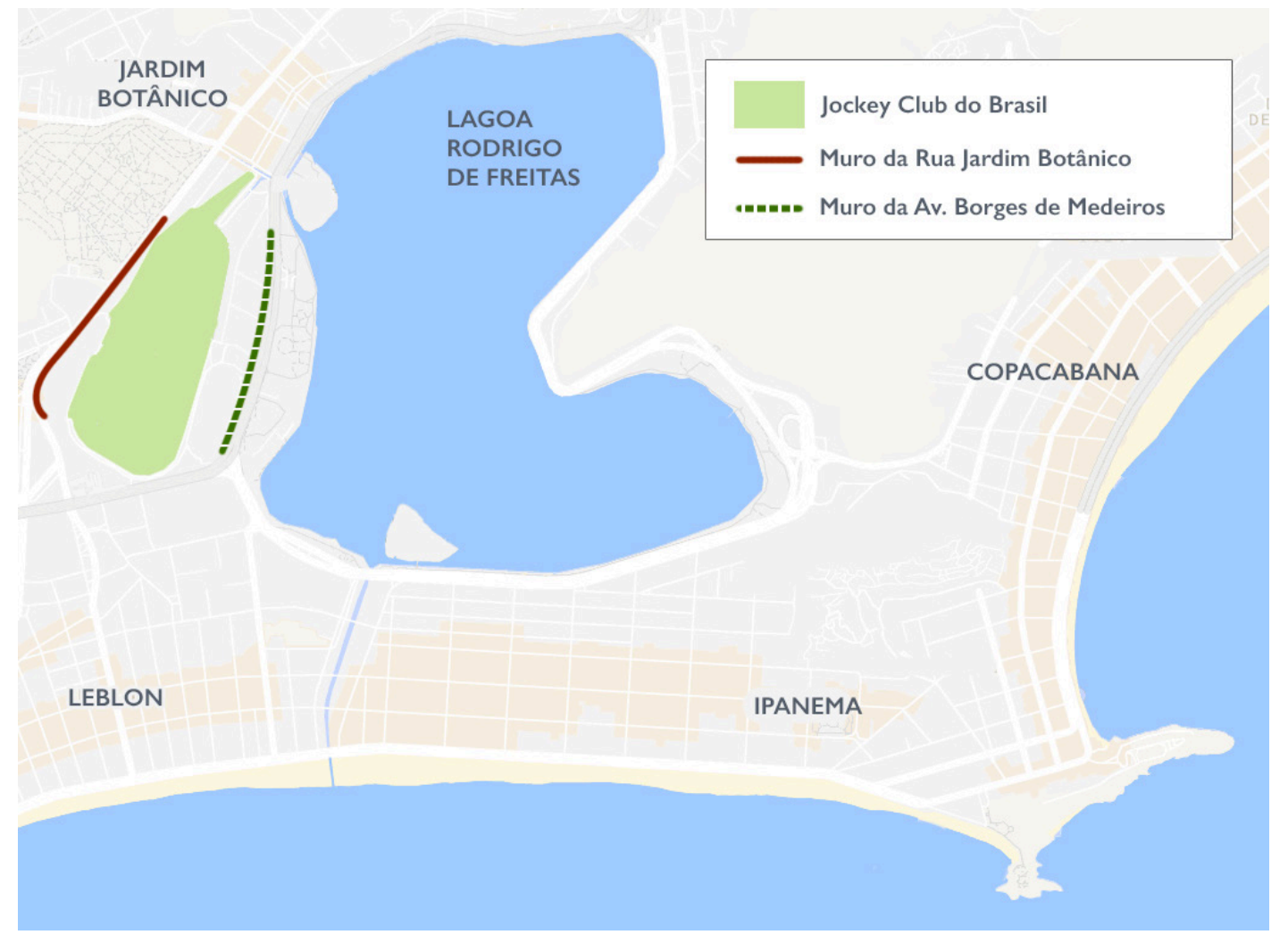

Figura 3 - Mapa da Zona Sul do Rio de Janeiro, com localização do Jockey Club do Brasil e seus muros da Rua Jardim Botânico e Av. Borges de Medeiros (Hely Costa Júnior).

O resultado foi um grande painel colorido (Figura 4), no entanto, de aspecto mais asséptico e organizado, pois parece ter sido pensado e criado para agradar os habitantes e enfeitar um dos pontos turísticos da cidade. Enquanto o muro da rua Jardim Botânico, que reunia não só os grafites, mas também pichações e inscrições, de forma efêmera, caótica, transformava-se em um palimpsesto formado por textos, imagens e cores, por meio da acumulação e da superposição 
de camadas de imagens e, também, da troca de significados no espaço e no tempo ao longo de mais de uma década.

No muro autorizado, os novos grafites funcionam mais como forma de embelezamento estético daquele espaço público (Banksy 2012), uma espécie de pintura mural, livre da áurea subversiva que costuma acompanhar o grafite, com direito à curadoria, ao patrocínio e ao apoio governamental. A própria pintura do novo muro foi celebrada com um evento que reuniu todos os grafiteiros, para conjuntamente elaborarem a pintura do projeto.

O grafite, enfim, foi se transformando em arte de galeria, perdendo a potência política e intervencionista que privilegiava a cidade como seu espaço de intervenção e discurso, colocando-o como resistência a um modelo de arte completamente sujeito aos mecanismos de controle de museus, galerias, bienais, publicidade. Ordem na cidade. Harmonia e beleza no desejo asséptico contemporâneo. Com isso, vê-se que o grafite, nascido dos conflitos raciais, da miséria econômica e cultural como um disparo na direção da ordem burguesa de homogeneização dos sujeitos nas metrópoles modernas, reinstala-se como o decorativismo morno em nome do novo nas mãos de atravessadores da arte, ávidos pela descoberta de talentos que venham azeitar as engrenagens do velho sistema de arte (Costa 2007: 181).

O amadorismo abriu espaço também para o profissionalismo. $\mathrm{O}$ traço tosco feito às pressas, muitas vezes na calada da noite, foi trocado pela estética dos desenhos refinados, produzidos à luz do dia e sob os holofotes da mídia. O grafite foi considerado por um largo período uma prática inaceitável e, até mesmo, um ato de vandalismo violento e marginal. Marginalidade que emerge tanto do anonimato ao qual ele estava associado, como também da agressividade simbólica e semiótica que a prática desempenha. Por tratar-se muitas vezes de linguagens irreconhecíveis e ilegíveis, ações anônimas e irrupção de propriedades privadas, o grafite gerava receios e, consequentemente, a rejeição àquelas escrituras, marcas e desenhos que surgiam de forma inesperada em locais inapropriados. Uma presença incômoda, que traz à tona a incompetência da autoridade e a precariedade e a impermanência da ordem, ao mesmo tempo em que revela o poder capilar daqueles que contradizem as convenções e violam as leis (Campos 2009).

Nesse sentido, pode-se dizer que as ações que cooptam e regulamentam a prática do grafite, como o "Jockey Club Arte Urbana", podem ser analisadas em uma aproximação aos conceitos de sociedade disciplinar e biopolítica, propostos por Foucault (2008), e de sociedade de controle, proposto por Deleuze (1992). Na modernidade foram criados diversos procedimentos discursivos e institucionais e dispositivos disciplinares sobre a educação, a docilização e a disciplinarização do corpo, sobre o qual eram instituídas proibições e obrigações: os sujeitos tornavam-se o objeto do controle e do poder cotidianamente exercidos sobre eles.

Esse poder tinha a intenção de extrair o potencial produtivo e neutralizar a capacidade política dos indivíduos (Foucault 2009). O homem tornava-se parte da engrenagem capitalista, na qual seu corpo estava a serviço da produção. Por meio das disciplinas, corpos dóceis, domados e adestrados eram produzidos e fabricados. Corpos mais fortes em termos econômicos e utilitários e inversamente mais fracos quanto às forças políticas. Ao dissociar o poder do corpo, a disciplina criava aptidões e aumentava capacidades, ao mesmo tempo em que invertia a energia e transformava esses corpos numa rigorosa relação de sujeição. O mesmo ocorre com o grafite, ao ser cooptado por projetos como o "Jockey Club Arte Urbana". Os grafiteiros, antes considerados transgressores e subversivos, tornam-se dóceis e aptos a produzirem de acordo com as regras impostas pela sociedade e pelo capital. 
A partir do século XVIII, as cidades passaram a ser consideradas espaços de circulação e fluxo, que dependiam do ordenamento e da eliminação de tudo aquilo que fosse perigoso. Podese dizer que tais funções têm ainda hoje reflexos na contemporaneidade e, sobretudo, no que diz respeito ao grafite contemporâneo. Tanto a pintura dos antigos grafites do muro do Jockey, na rua Jardim Botânico, quanto a do novo mural na Lagoa Rodrigo de Freitas têm em comum uma necessidade de, o que se pode chamar aqui, higiene visual, ou seja, uma necessidade de manter o muro com aspecto limpo, asséptico e renovado, livre do que poderia ser considerado poluição visual. Ao mesmo tempo, os grafiteiros, já tidos como delinquentes por rabiscarem muros e paredes, tornaram-se agentes com a função de embelezar a cidade com seus traços, cores e desenhos.
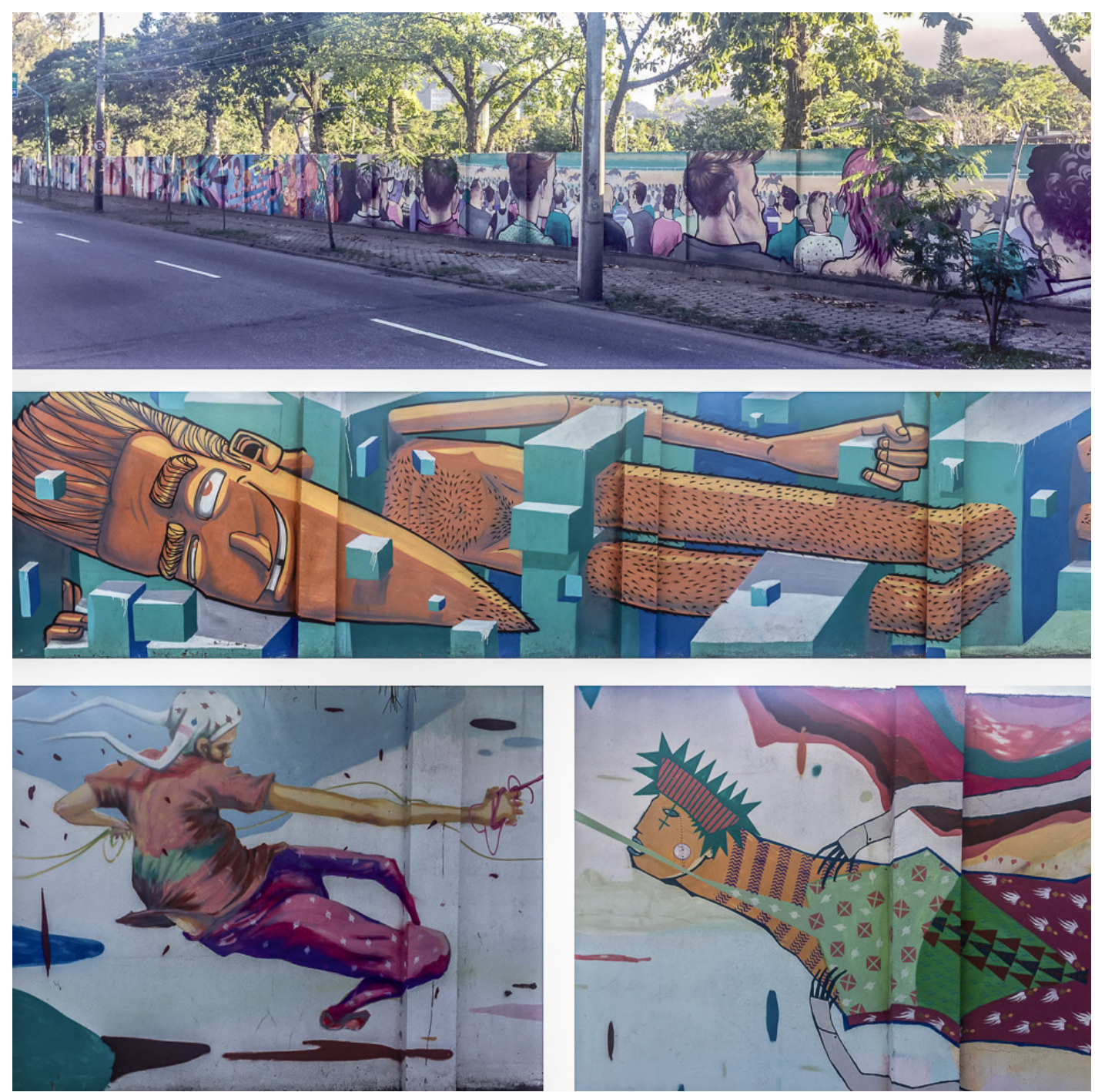

Figura 04 - Panorama e detalhes do novo mural no muro do Jockey Club Brasileiro, na Av. Borges de Medeiros, em frente à Lagoa Rodrigo de Freitas (fotos Hely Costa Jr.).

Em meados do século XX, de acordo com Deleuze (1992), as sociedades disciplinares são substituídas pela chamada sociedade de controle, a partir do florescimento de tecnologias audiovisuais, internet, cartões de crédito etc. Uma sociedade que, ao contrário da sociedade disciplinar, não atua mais como um molde disciplinar rígido, mas por meio de modulações flexíveis e um constante aperfeiçoamento, nos quais os mecanismos de comando são implantados congnitivamente pelos corpos e cérebros dos indivíduos e, por isso, parecem ser mais democráticos e 
inerentes ao campo social (Negri e Hardt 2001). Estruturas de controle que agem como um aprimoramento das disciplinas, organizadas em circuitos maleáveis, que passam a ser compreendidos para além dos espaços antes determinados das instituições.

Na pintura do "Jockey Club Arte Urbana", o grafite abandonou a transgressão e perdeu sua potência intervencionista. A subversão, o caos e as camadas de tinta sobrepostas foram trocados pela ordem, pela harmonia e pelo ideal de beleza: os grafites tornaram-se, ali, murais decorativos: mais próximos de um produto ou de uma mercadoria com forte apelo estético. Tal como argumenta Žižek (2003), o aspecto primordial do capitalismo tardio é a forma como a transgressão foi normalizada. No processo de transposição, no qual o trabalhador/cidadão torna-se um consumidor, tudo o que a sociedade disciplinar proibia o consumismo contemporâneo encoraja e exige.

Nesse sentido, o grafite e sua estética tornaram-se, na sociedade de controle, um produto a ser comercializado. Não no sentido de mercadoria, visto que já não são aquilo de mais importante produzido pelas empresas, mas no sentido de conhecimento e produto cultural, que só se tornam eficazes em sua própria reprodução e se produzem a partir de uma criação cooperativa, como afirma o grafiteiro Toz.

Eu me formei em design gráfico, então o meu processo de criação é bem parecido com o de design gráfico (...). Uma metodologia bem parecida com a de design gráfico e normalmente eu tenho a cabeça de aplicar minha arte em outras coisas, não só numa exposição, agora eu vou fazer uns toy arts de verdade, então, isso é uma coisa que me interessa, porque eu venho dessa formação de design, então é uma parada que eu fico amarradão (...). Quando eu comecei a fazer grafite, não existia no mercado alguém que fizesse design e grafite. Então a gente montou um escritório de design chamado Motim. Nesse escritório de design, a gente teve muito essa função de transformar, materializar a linguagem que estava rolando e que rola até hoje de street art em projetos comerciais. Então a Vivo, a Tim, a Oi, todas elas requisitaram muito a gente pra fazer. No começo, quando eu estava mais atuante neste mercado de design, eu fiz de tudo (Toz, em entrevista ao autor em 19 de outubro de 2014).

Nesse cenário, o capital apreende o grafite e o sujeito grafiteiro para dentro de suas empresas e instituições, a fim de melhor lucrar com as redes sociais, reformulando-se e reestruturando-se ao máximo possível para libertar-se da fabricação de mercadorias e concentrar-se mais na comunicação e nos processos imateriais (Trindade e Santos 2002). Assim, os grafiteiros podem desterritorizarem-se da marginalidade e reterritorizarem como sujeitos produtivos, com uma nova utilidade e também uma fonte de renda e reconhecimento.

O território pode ser relativo tanto a um espaço vivido, quanto a um sistema percebido no seio da qual um sujeito se sente "em casa". O território é sinônimo de apropriação, de subjetivação fechada sobre si mesma. Ele é o conjunto de projetos e representações nos quais vai desembocar, pragmaticamente, toda uma série de comportamentos, de investimentos, nos tempos e nos espaços sociais, culturais, estéticos, cognitivos (Guattari e Rolnik 1986:323).

De acordo com Deleuze e Guattari (1995b), um território criado através de quatro elementos: agenciamentos maquínicos de corpos, agenciamentos coletivos de enunciação, da desterritorialização e a reterritorialização. Portanto, ultrapassando o espaço geográfico. Enquanto os agenciamentos maquínicos de corpos são máquinas sociais e dizem respeito às relações entre os corpos em uma sociedade, o agenciamento coletivo de enunciação diz respeito a um sistema de signos partilhados, a códigos, a palavras e a símbolos. Os agenciamentos maquínicos de corpos (conteúdo) possuem uma forma, tal qual os agenciamentos coletivos de enunciação 
(expressão). Ambos os agenciamentos percorrem e intervêm um ao outro em um movimento mútuo, recíproco e sem hierarquias, e assim o território se constitui.

Nesse sentido, um muro grafitado é um território formado por agenciamentos maquínicos de corpos (o próprio muro, as técnicas de grafite, o corpo dos grafiteiros e as multiplicidades que os atravessam) e um agenciamento coletivo de enunciação (os símbolo, signos, desenhos e palavras por eles pintados e representados).

Um território sempre comporta dentro de si vetores de desterritorialização e de reterritorialização. A desterritorialização é o movimento pelo qual se renuncia o território, uma linha de fuga na qual os agenciamentos se desterritorializam. Enquanto a reterritorialização é o impulso de composição do território, no qual os agenciamentos se reterritorializam como novos agenciamentos maquínicos de corpos e coletivos de enunciação (Deleuze e Guattari 1997:224). Ambos são ações intrínsecas: se há um movimento de desterritorialização, há também um movimento de reterritorialização, um fluxo constante. Nesse fluxo, os grafiteiros passam de um território a outro, da marginalidade à legitimação, das ruas às galerias e trabalhos remunerados e vice-versa, abandonando (mas não destruindo) e criando novos territórios.

$\mathrm{Na}$ rua geralmente a gente faz um trabalho em um dia, poucas horas, às vezes rápido e a gente faz só com spray (...). Então você tem uma gama de cores enorme, possibilidades enormes com o spray. Mas é aquilo, você faz de forma efêmera, o grafite é efêmero. (...) Já numa tela não! A pessoa vai entrar numa galeria ou em uma exposição e ter todo o tempo do mundo que ela quiser pra sentar ali na frente da tua tela, olhar todos os detalhes, olhar de perto, de longe... Enfim, ela tem um tempo de apreciação e de entendimento da obra completamente diferente do que ele tem na rua. Eu demorei pra entender isso, quando eu comecei a fazer coisas na galeria eu trazia um pouco muito (sic) da rua e como se eu colocasse dentro de uma gaiola a rua. Hoje em dia eu já penso nessa extensão do trabalho, de você se aproximar mais, dar um zoom no seu trabalho que a rua não te permite, porque a rua ela é rápida, ela é ligeira, tem tempo, tem prazo, você não pode ficar dando mole com celular, nem ficar olhando. Ela tem um ritmo e não é você que determina, é o próprio dia a dia daquele grafite. E na galeria não, tem um ambiente condicionado pra receber uma obra de arte, pra receber aquele público que está ali para apreciar. Então pra mim, isso faz toda a diferença (Toz, em entrevista ao autor em 20 de outubro de 2014).

O grafite na galeria, a orientação que a gente sempre teve [dos marchands], é falar que, na verdade, é um trabalho de arte que vem da transferência do artista na rua (...). Eu pessoalmente levo para os espaços fechados um outro trabalho meu, que não necessariamente eu considero grafite, são desdobramentos, da mesma essência, das minhas vivências (Panmela Castro, em entrevista ao autor no dia 15 de outubro de 2014).

$\mathrm{Na}$ rua você tem liberdade total, você não está preocupado em vender. Quando você bota um trabalho na galeria sua expectativa é vender. Ele está dentro de uma galeria, que sua função é vender arte. Então você tem uma preocupação estética um pouco maior, preocupação até na mistura de materiais. Você na vai utilizar só spray, você vai utilizar técnica uma mista, vai utilizar acrílica, spray óleo, você está livre. E na rua você está ali só usando spray, fazendo o que você quer, sem direcionamento, sem ter que querer "agradar" ninguém (BR, em entrevista ao autor em 20 de outubro de 2014).

As falas dos grafiteiros Toz, Panmela Castro e BR mostram claramente esses movimentos de desterritorialização e reterritorialização, assim como a do marchand, Ricardo Kimaid, dono da Galeria Movimento. Segundo ele, os grafiteiros reterritorializam-se como artistas plásticos a partir do momento em que entram na galeria, onde são produzidas unicamente obras de arte que, para serem criadas, precisam ser pensadas com tempo e dedicação.

$\mathrm{Na}$ rua eles fazem grafite, ilegalmente, fazem na pressa. Mesmo pensamento que um pichador, marcar território, deixar sua marca... Quando passa para uma tela é um outro conceito, eles vão para um ateliê, pesquisam, trabalham as cores, as telas, a calma é importantíssima, como um artista plástico. Claro que muitos 
usam também o spray como ferramenta, mas o processo é igual ao de um artista plástico. Existem ótimos grafiteiros, muito bons mesmo, mas quando tentam ir para a tela, nossa, perdem muito. Essa é a dificuldade que muitos grafiteiros não conseguem entender, pintar uma tela não é tão simples, tem muita coisa envolvida por trás. (Ricardo Kimaid, em entrevista ao autor em 20 de janeiro de 2016).

Em troca de fama ou dinheiro, os grafiteiro reterritorializam-se em sujeitos úteis à sociedade, que passa então a enxergá-los como benfeitores que colorem e transformam a cidade. Assim, os muros viram painéis decorativos e suas temáticas sofrem influência de quem os contrata. No entanto, tais táticas não impedem que os mesmos grafiteiros realizem, em outros espaços da cidade, grafites livres ou considerados subversivos, que não obedeçam às regras do governo ou de patrocinadores. Nesse contexto, percebe-se uma consciência reflexiva por parte de alguns grafiteiros às tentativas de controle e docilização de suas práticas: ao se reterritorizarem no mercado, os trabalhos comerciais remunerados garantem a continuidade e o financiamento de trabalhos subversivos ou até mesmo sociais.

Tem os grafiteiros que vão pintar muito na rua, que vão fazer muita coisa ilegal, vão fazer muito trem, vai fazer menos trampo comercial. Enfim, cada um é livre pra fazer o que acha certo. Eu tento equilibrar as coisas, tento fazer bastante coisa na rua e tento equilibrar também porque eu vivo disso. Então eu transito aí nesses dois universos (...) Eu estou muito mais interessado em virar parceiros das marcas para que eu possa realizar meus projetos sociais, inverter, usar a mídia e a força deles pra transformar isso em viabilidade para o meu trabalho também (...). É isso, não é só por dinheiro, tem outras coisas que são avaliadas (...) É pintar livremente, pintar com liberdade, pintar com vontade de fazer, sem ter nenhum vínculo com nada que te prenda, que te limite o que você vai fazer, tanto no espaço que você vai fazer e o que você vai fazer, desenhar (Toz, em entrevista ao autor em 20 de outubro de 2014).

Todo mundo quer viver do que gosta de fazer, quem reclama disso são pessoas que não conseguem vender seu trabalho ainda, não conseguem enxergar que eles podem viver do que eles fazem. Eu tenho formação de designer, então na escola de design você aprende a vender sua arte. Eu nunca tive problemas com isso, nosso grupo de forma geral teve uma receptividade muito grande no mercado e uma facilidade de trabalhar com o mercado, então pra gente sempre foi muito natural. Nunca tivemos problema ou preconceito nosso com isso. A gente faz grafite na rua, de graça, de verdade, continua fazendo até hoje, independe de estar fazendo trabalho [comercial] (BR, em entrevista ao autor em 21 de outubro de 2014).

Dinâmicos e fragmentados, os antigos e novos grafites do muro do Jockey podem ser pensados como parte do conjunto de relações de força que transitam e circulam entre dominantes e dominados, estabelecendo singularidades e trazendo à tona a questão da conexão entre indivíduos, no que se refere às leis, instituições, ideologias, ou mesmo às estruturas ou aos mecanismos de poder (Foucault 1985). Poder que tem como principal característica engendrar ligações entre indivíduos ou grupos e diz respeito a relacionamento entre parceiros, a ações que provocam e desencadeiam outras ações. Relações que estão em constante e eterno enfrentamento assim como o grafite, que pode ser pensado

(...) como uma multiplicidade de correlações de força imanentes ao domínio onde se exercem e constitutivas de sua organização; o jogo que, através de lutas e afrontamentos incessantes as transforma, reforça, inverte; os apoios que tais correlações de força encontram uma nas outras, formando cadeias ou sistemas ou, ao contrário, as defasagens e contradições que as isolam entre si; enfim, as estratégias em que se originam e cujo esboço geral ou cristalização institucional toma corpo nos aparelhos estatais, na formulação da lei, nas hegemonias sociais (Foucault 1988: 88).

Grafite e poder referem-se a relacionamentos entre parceiros, a ações que provocam e desencadeiam outras ações, técnicas e estratégias que permeiam, produzem coisas, levam ao prazer, formam saberes e motivam discursos. As atitudes do governo, da polícia, da mídia e da população em relação ao grafite e aos grafiteiros são um exemplo dessa relação de forças entre 
dominantes e dominados. Tal qual um poder que se pratica, o grafite supõe lutas, afrontamentos constantes, uma dinâmica que se exerce por meio de manobras, estratégias, técnicas e táticas imputáveis a uma apropriação. Um poder que pode incluir ou excluir os indivíduos da sociedade. Para Negri e Hardt (2001), o poder apregoa um controle que se espalha pela consciência e também pelos corpos da população, bem como, concomitantemente, por meio das totalidades das relações sociais.

Assim, o espaço de fluxo e de constante transformação torna-se um espaço de renovação da percepção da experiência: um muro que pode passar despercebido aos olhos dos habitantes, ganhando uma nova dimensão. "O espectador passa de uma contemplação deambulatória de objetos autônomos, apresentados num contexto neutro, para viver uma experiência estética" (Peixoto 2002: 18). Uma experiência estética que altera a contemplação de um muro, dando-lhe novas percepções e ampliando seus significados.

\section{Considerações Finais}

O grafite vem assumindo diferentes papéis de acordo com a época, o local e o contexto social em que está inserido. Uma prática em constante processo de transformação, que modifica sua essência e envolve a subjetividade daqueles que a produzem. Se há algumas décadas o grafite era sinônimo de transgressão e marginalidade, de modo de expressão e comunicação daqueles que não tinham voz, espaço ou autonomia para fazê-lo nos veículos oficiais, hoje ele se tornou um produto respeitado, legalizado e, sobretudo, comercialmente valorizado.

Ao longo dos últimos anos a transgressão e o capitalismo passaram a envolver-se de forma cada vez mais intensa e aberta. No Rio de Janeiro, essa relação entre o marginal e o capital é claramente percebida no muro do Jockey Club, passando pela desterritorialização e pela reterritorialização que envolvem grafiteiros, empresas, marchands e instituições.

Pode-se dizer que, em grande parte, o grafite passou a ser definido pelo poder econômico. Hoje, o local onde ele está inserido, sua estética, sua temática e, principalmente, os nomes dos grafiteiros que se destacam são determinados pelo capital. Assim, os grafiteiros se desterritorializam da transgressão e da marginalidade para reterritorializarem em outros espaços, onde encontram reconhecimento e o valor de troca.

Mercantilizado, o grafite tornou-se um poderoso aliado não só do Rio de Janeiro, mas de todos os grandes centros urbanos. Ele já não suja e "emporcalha" os muros da cidade, desafiando as leis e os procedimentos de controle. Os coloridos painéis que adornam os muros, paredes e laterais dos prédios têm a função de colorir a cidade e alegrar os ambientes: um antídoto ao caos, à frieza e à impessoalidade da vida na metrópole. No local onde os indivíduos estão submissos à razão, à racionalidade, os grafites coloridos substituem o cinza, o sujo e o feio por imagens que suavizam o cotidiano, ornamentam os espaços e valorizam a cidade.

De modo geral, pode-se perguntar se todas essas estratégias e transformações seriam maneiras eficazes de alienação do grafite. Estratégias que, como os dispositivos descritos por Foucault (1998), podem ser pensadas como uma rede de artimanhas heterogêneas entre si, que envolvem jogos de objetivação e subjetivação. Como, por exemplo, os discursos da mídia sobre 
o grafite, as instituições que o cooptam, leis e regulamentos que o legalizam, assim como decisões, medidas administrativas, enunciados, proposições filosóficas e morais. Táticas que colaboram diretamente com as ações de controle dos corpos e espaços da cidade. Dóceis, ocupados e produtivos, os grafiteiros estão mais interessados em atividades que podem gerar benefícios, oportunidades, lucro e reconhecimento para seu trabalho. Elementos que, consequentemente, num círculo virtuoso, resultam em mais oportunidades, lucro e reconhecimento. Nesse contexto, a sedução gerada pelo capital é mais recompensadora que a pintura fugaz e efêmera dos muros da cidade.

\section{REFERÊNCIAS BIBLIOGRÁFICAS}

Baker, Alex. 2010. Theorizing the "street" in the street art: some thoughts on the urban dialogue. In Museum of Contemporany Art San Diego (Org.). Viva La Revolución: A dialogue with the urban landscape. San Diego.

Banksy. 2012. Guerra e Spray. Rio de Janeiro: Intrínseca.

Campbell, Brígida. 2015. Arte para uma cidade sensível. São Paulo: Produções Invisíveis.

Campos, Ricardo. 2009. Entre as luzes e as obras da cidade: visibilidade e invisibilidade no graffiti. In Etnográfica, v. 13 (1).

Canclini, Nestor Garcia. 2008. Culturas híbridas: estratégias para entrar e sair da modernidade. 4 ed. São Paulo: EdUSP.

Canevacci, Massimo. 2005. Culturas eXtremas: mutaçôes juvenis nos corpos das metrópoles. Rio de Janeiro: DP\&A.

Certeau, Michel de. 1994. A invenção do cotidiano: artes de fazer. Petrópolis, RJ: Vozes.

Costa, Luizan Pinheiro da. 2007. Grafite e pichação: institucionalização e transgressão na cena contemporânea. In: III Encontro de História da Arte - IFCH / UNICAMP, 2007, Campinas. Anais... Campinas: Unicamp. p. 177 a 183.

Deleuze, Gilles. 1992. O que é a filosofia?. São Paulo: Editora 34.

Deleuze, G.; Guattari, F. 1995a. Mil platôs: capitalismo e esquizofrenia. Vol.1. São Paulo: Editora 34. 1995b. Mil platôs: capitalismo e esquizofrenia. Vol.2. São Paulo: Editora 34.

Douglas, Mary. 1976. Pureza e perigo. São Paulo: Perspectiva.

Ferrel Jeff. 1996. Crimes of style: urban graffiti and the politics of criminality. Boston, MA: Northastern.

Foucault, Michel. 2005. Em defesa da Sociedade. São Paulo: Martins Fontes,. 1988. História da sexualidade. Rio de Janeiro: Edições Graal. 1985. Microfísica do Poder. 5 ed. Rio de Janeiro: Graal. 2008. Nascimento da Biopolitica. São Paulo: Martins Fontes. 2009. Ditos e escritos: estética - literatura e pintura, música e cinema. Motta, Manoel Barros da (Org.). Tradução de Vera Lúcia Avellar Ribeiro. Rio de Janeiro: Forense Universitária.

Guattari, Félix. 1987. Revolução Molecular: pulsações políticas do desejo. São Paulo: Brasiliense. .1988. O Inconsciente Maquinico: ensaios de esquizo-análise. Campinas: Papirus.

Guattari, F.; Rolnik, S. 1996. Micropolitica: cartografias do desejo. Petrópolis: Vozes.

Goodsell, Charles. 2003. "The Concept of Public Space and Its Democratic Manifestations," American Review of Public Administration, 33 (4), 361-83. 
Harvey, David. 2013. O direito à cidade. Revista Piauí, São Paulo, Julho de 2013. Disponível em <http://revistapiaui.estadao.com.br/materia/o-direito-a-cidade/> acesso em 20 de dezembro de 2014.

2002. O espaço como palavra-chave. Revista GEOgraphia. Rio de Janeiro: UFF, v. 14, n. 28, p. 8 - 39.

Lefebvre, Henri. 2000. A produção do espaço. Trad. Doralice Barros Pereira e Sérgio Martins (do original: La production de l'espace. 4e éd. Paris: Éditions Anthropos). 2001. O direito à cidade. São Paulo: Centauro.

Lima, Ludmilla de. 2014. Em reforma de muro, Jockey Club apaga grafites e provoca polêmica: Com tinta bege, clube cobriu obra de arte urbana coletiva e alega que medida é para revitalização, Jornal O Globo, Rio de Janeiro, 24 de março de 2014. Disponível em <http:// oglobo.globo.com/rio/em-reforma-de-muro-jockey-club-apaga-grafites-provoca-polemica-11963007\#ixzz430LvPABN> acesso em 15 de setembro de 2015.

Negri, A.; Hardt, M. 2001. Império. Rio de Janeiro e São Paulo: Record.

Peixoto, Nelson Brissac (org.). 2002. Intervenções urbanas: arte / cidade. São Paulo: SENAC.

Ramos, Célia Maria Antonacci. 1994. Grafite Pichação E̋ Cia. São Paulo: Annablume.

Ritter, Vivian Fetzner. 2014. O espaço e a biopolítica. In: Poliética, São Paulo, v. 2, n. 1, pp. 112137.

Silva, A. M. F.; Pereira, M. S. 2012. Discursos sobre a arte urbana no Rio de Janeiro: a legitimação do grafite nas ruas e galerias de arte da cidade. Rio de Janeiro. Dissertação de Mestrado Departamento de Comunicação Social, Pontifícia Universidade Católica do Rio de Janeiro. Trindade, A. L.; Santos, R. (orgs). 2002. Multiculturalismo: mil e uma faces da escola. $3^{\circ}$. Ed. - Rio de Janeiro: DP\&A.

Žižek, Slavoj. 2003. The Puppet and the Dwarf. Cambridge, MA: The MIT Press.

\section{From tRANSGRESSION TO CONTROL: AN ANALYSIS OF GRAFFITI ON THE WALL OF RIO de JaNeIRo's Jockey Club}

This article analyzes the graffiti on the wall of the Jockey Club in Rio de Janeiro and its relations with territory, market and capital. The enormous wall, which has been covered with graffiti in a spontaneous and "transgressive" way since the beginning of the 2000s, has undergone a remodelling and restoration in March, 2014. This intervention has erased the images that covered the over two-thousand-meter wall, causing polemic and indignation amongst graffiti artists and the population. Months later, a new panel was created substituting the old one. However, this was done in an "official" way, with a curatorship that chose artists, sponsorship and state support. The author's analysis of the transformation of the "transgressive" wall into a "controlled" one is mainly based on the concepts of power and disciplinary society proposed by Michel Foucault, and Deleuze's and Guattari's concepts of a society of control, deterritorialization and reterritorialization.

Keywords: graffiti, transgression, power, disciplinary society, society of control, Rio de Janeiro

Recebido em: 2016-11-29

Aceitado em: 2017-04-25 